\title{
Clinical Study Activity Relationship Comment
}

National Cancer Institute

\section{Source}

National Cancer Institute. Clinical Study Activity Relationship Comment. NCI Thesaurus.

Code C70929.

An additional description of the relationship between the clinical study activities specified in a study protocol. It might refer to a temporal or sequential relationship, or indicate the possibility of performing a particular type of activity as a substitute for another one. 